\author{
Joyce Wahr \\ Jeffrey Vender \\ Hugh C. Gilbert \\ Bruce Spiess \\ Jan C.Horrow \\ Rosemarie Maddi
}

\section{Effect of Propofol With and Without EDTA on Haemodynamics and Calcium and Magnesium Homeostasis During and After Cardiac Surgery}

This work was supported by a grant from AstraZeneca, Wilmington, Delaware.

\section{J.Wahr (๘)}

University of Michigan,

Department of Anesthesia,

1500 E. Medical Drive, Ann Arbor,

MI 48109-0048, USA

e-mail: jwahr@umich.edu

Tel.: +734-936-8081

Fax: +734-936-9091

J. Vender $\cdot$ H. C. Gilbert

Evanston Hospital, Division of Anesthesia,

Evanston, IL

\section{B. Spiess}

University of Washington School of Medicine, Department of Anesthesia, Seattle, WA

\section{J. C. Horrow}

MCP-Hahnemann University, Department of Anesthesiology, Philadelphia, PA

R. Maddi

Brigham and Women's Hospital, Department of Anesthesia, Boston, MA
Abstract Objective: To determine the effect of the addition of disodium edetate (EDTA) to propofol on haemodynamics, ionised calcium and magnesium serum concentrations, and adverse events during cardiac surgery.

Design: Double-blind, randomised, multicenter trial.

Setting: Operating room and intensive care unit of 5 academic health centres.

Patients: A total of 102 evaluable patients, aged 34 to 85 years, undergoing first-time, elective coronary artery bypass graft surgery. Interventions: Comparison of propofol with EDTA and propofol without EDTA, each in conjunction with the opioid sufentanil, for intraoperative anaesthesia and postoperative sedation.

Measurements and Results: There were no significant differences at any time between the two formulations in any clinical chemistry measurements, including ionised calcium, ionised magnesium, total calcium, parathyroid hormone, blood urea nitrogen, creatinine, sodium, potassium, and phosphate. During bypass, the mean concentration of ionised calcium decreased to below the normal range, but the decrease was similar in both groups (propofol with EDTA, $0.98 \pm 0.07 \mathrm{mmol} / \mathrm{L}$ $[\mathrm{N}=51]$; propofol, $0.99 \pm 0.10 \mathrm{mmol} /$ $\mathrm{L}[\mathrm{N}=51] ; p=\mathrm{NS})$. Calcium concentration returned to normal after rewarming. Mean ionised magnesium concentrations remained within normal limits in both groups. Similarly, there were no clinically meaningful differences between treatments with respect to haemodynamic variables, efficacy variables, or incidence of adverse events.

Conclusions: The inclusion of EDTA in the current formulation of propofol appears to have no significant effects on calcium and magnesium profiles, renal function, haemodynamic variables, or other indicators of safety and efficacy during intraoperative anaesthesia and postoperative sedation in patients undergoing cardiac surgery.

Key words Propofol - Cardiac surgical procedures $\cdot$ Sedation, homeostasis $\cdot$ Disodium EDTA $\cdot$ Chelating agents

\section{Introduction}

Electrolyte disturbances can occur from a variety of causes during cardiac surgery, including haemodilution from pump prime solutions, the chelating actions of preservatives in blood products, and the effects of drugs such as heparin, protamine, and diuretics [1-3]. Abrupt changes in the serum concentrations of potassium, sodium, calcium, and magnesium can be detrimental to this patient population [4]. Low concentrations of the divalent cations calcium and magnesium can lead to dysrhythmias and cardiac depression [2,3]. Thus, for patients un- 
dergoing cardiac surgery, it is important that anaesthetic and sedative agents do not compound the electrolyte changes that typically occur during the procedure.

Propofol (DIPRIVAN ${ }^{\circledR}$, AstraZeneca, Wilmington, Delaware) is an intravenous sedative-hypnotic agent with a long history of safety and efficacy for the induction and maintenance of anaesthesia. Propofol has demonstrated clinical utility both as primary and adjunctive anaesthesia during surgeries requiring cardiopulmonary bypass (CPB) [5-9] and as postoperative sedation in the cardiac intensive care unit (ICU) [10]. Propofol has biochemical, metabolic, and haemodynamic effects during CPB similar to those of other cardiac anaesthetic regimens $[6,7,9]$; in addition, its inherent characteristics lead to modulated postoperative haemodynamic responses during ICU sedation [10] and faster recovery from anaesthesia [11].

Propofol has undergone a formulation change since some of the early studies in cardiac patients were published. In 1996, disodium edetate $0.005 \%$ (ethylenediaminetetraacetic acid [EDTA]) was added to the formulation to help retard the growth of microbial organisms due to accidental extrinsic contamination [12-15]. EDTA is a strong chelator of cations, and this chelation activity could theoretically pose problems for patients undergoing cardiac surgery. Use of EDTA has been shown to decrease serum concentrations of ionised calcium and magnesium [16] and has been reported to induce hypocalcaemia and acute toxicity (eg, renal) [17]. Based on its calcium chelation properties, EDTA has been used to treat hypercalcaemia in humans.

The primary objectives of this study were to evaluate the effects of propofol with and without EDTA on haemodynamics, calcium and magnesium homeostasis, renal function and adverse effects in patients undergoing cardiac surgery. Both formulations were tested in 2 commonly used anaesthetic regimens: the first as a primary anaesthetic and the second as an adjuvant to a narcotic anaesthetic.

\section{Materials and methods}

With the approval of each local institutional review board, patients scheduled for first-time coronary artery bypass graft or valvular surgery were approached about participation. To be eligible, the planned surgery had to include CPB and the patient had to be a candidate for early endotracheal extubation. Patients with severely compromised cardiac function (ejection fraction $<25 \%$ ), an intraaortic balloon pump, hepatic or renal insufficiency, severe multiorgan dysfunction, or severe chronic respiratory disease or those undergoing surgical procedures to correct atrial septal defects were excluded. Patients were also excluded if they underwent more than 12 consecutive hours of artificial ventilation or if the CPB period was expected to be $>3$ hours.

The study was conducted at 5 trial sites between February 23, 1995, and October 7,1995. To test propofol with and without EDTA as both the primary anaesthetic agent and as an adjuvant agent, a fac- torial design was used. Patients were first randomised to receive in a blinded fashion 1 of 2 formulations of propofol: propofol without EDTA (propofol) or propofol with EDTA (propofol EDTA). Patients were then further randomised to receive in an open fashion either a high or low dosage of the formulation. The assigned dosage determined whether the propofol formulation would be the primary (high dose) or adjunctive (low dose) anaesthetic agent.

The 2 treatment formulations of propofol were (1) the injectable emulsion DIPRIVAN ${ }^{\circledR}$ that was on the market at the time the study was initiated (ie, propofol with soybean oil [100 mg/ $\mathrm{mL}$, glycerol [22.5 mg/mL], and egg lecithin [12 mg/mL]) and (2) the formulation of DIPRIVAN ${ }^{\circledR}$ that is currently marketed (as above with the addition of $\mathrm{Na}_{2}$ EDTA [0.005\%]).

At induction, patients randomised to propofol EDTA or propofol as the primary anaesthetic agent received approximately 1.0 to $1.5 \mathrm{mg} / \mathrm{kg}$ (20 mg every $10 \mathrm{~s}$ ) of their assigned formulation until loss of consciousness. They also received a bolus injection of sufentanil (the adjunctive anaesthetic) $0.5 \mu \mathrm{g} / \mathrm{kg}$ (at least 5 minutes before intubation) or an increase in the trial drug infusion rate if they had hypertension. During maintenance of anaesthesia, these patients received propofol EDTA or propofol at a rate of 100 to $200 \mu \mathrm{g} / \mathrm{kg}$ per min, adjusted to clinical response, along with sufentanil for analgesia at a rate of 0.005 to $0.0075 \mu \mathrm{g} / \mathrm{kg}$ per min.

Patients randomised to propofol EDTA or propofol as the adjunctive anaesthetic agent were given approximately 1.0 to $5.0 \mu \mathrm{g} /$ $\mathrm{kg}$ of sufentanil in divided doses until loss of consciousness, with their assigned treatment formulation administered as needed. During maintenance of anaesthesia, they received propofol EDTA or propofol at a rate of 50 to $100 \mu \mathrm{g} / \mathrm{kg}$ per min, titrated to clinical response, with infusion of sufentanil as the primary anaesthetic agent at a rate of 0.02 to $0.03 \mu \mathrm{g} / \mathrm{kg}$ per min.

All patients received vecuronium to facilitate intubation. Benzodiazepines or volatile anaesthetic agents were not permitted. If hypertension occurred during surgery, the infusion rate of the primary anaesthetic could be increased. Alternatively, patients randomised to propofol EDTA or propofol as the primary anaesthetic could be given a $0.5-\mathrm{mg} / \mathrm{kg}$ bolus injection of their assigned formulation or a $5-\mu \mathrm{g} / \mathrm{kg}$ bolus of sufentanil, whereas patients randomised to propofol EDTA or propofol as the adjunctive anaesthetic could be given a $5-\mu \mathrm{g} / \mathrm{kg}$ bolus injection of sufentanil. Nitroglycerin, sodium nitroprusside, or esmolol were also allowed for treatment of hypertension not controlled by anaesthetic titration. Interventions to control hypotension could include treatment with vasopressors, inotropes, or fluids as well as a reduction in or intermittent interruption of the primary anaesthetic agent. After surgery, a physician who was blinded to the assigned anaesthetic regimen evaluated patients for extubation.

To determine possible treatment effects on calcium and magnesium homeostasis, ionised calcium and magnesium concentrations were assessed before induction of anaesthesia (baseline); 15 minutes after induction of anaesthesia; 15 minutes after initiation of bypass; 15,30 , and 45 minutes after bypass; at arrival in the ICU; and 1 hour after extubation. Concentration of total calcium was determined at baseline, at arrival in the ICU, and 1 hour after extubation; concentration of parathyroid hormone (PTH) was measured at baseline and 1 hour after extubation. Renal function was assessed by measuring serum concentrations of blood urea nitrogen (BUN) and creatinine at baseline, at arrival in the ICU, and 1 hour after extubation.

All analyses were performed using serum samples except ionised calcium and ionised magnesium concentrations, which were measured in whole blood (Nova Biomedical, Waltham, Massachusetts). Serum samples for PTH were frozen and maintained at or below $-20^{\circ} \mathrm{C}$ until shipped to a laboratory (Bowman Gray School of Medicine, Winston-Salem, North Carolina) for analysis. The ra- 
Table 1 Demographic and other baseline characteristics of patients

\begin{tabular}{lcc}
\hline Variable & Treatment Formulation & \\
\cline { 2 - 3 } & $\begin{array}{l}\text { Propofol EDTA } \\
(\mathrm{N}=51)\end{array}$ & $\begin{array}{c}\text { Propofol } \\
(\mathrm{N}=51)\end{array}$ \\
\hline Age $(\mathrm{y})$, mean $\pm \mathrm{SD}$ (range) & $59.6 \pm 9.5(40-77)$ & $62.8 \pm 11.0(34-85)$ \\
Weight $(\mathrm{kg})$, mean $\pm \mathrm{SD}^{*}$ (range) & $85.2 \pm 13.8(55.5-118.2)$ & $79.8 \pm 14.8(48.6-117.0)$ \\
Height $(\mathrm{cm})$, mean $\pm \mathrm{SD}$ (range) & $173.1 \pm 9.0(150.0-190.5)$ & $171.3 \pm 9.3(149.9-188.0)$ \\
Gender $(\mathrm{N})$ & & \\
Male & 39 & 38 \\
Female & 12 & 13 \\
Race $(\mathrm{N})$ & & \\
White & 49 & 49 \\
Other & 2 & 2 \\
ASA classification $(\mathrm{N})$ & & 1 \\
I & 0 & 2 \\
II & 4 & 41 \\
III & 40 & 7 \\
IV & 6 & 0 \\
V & 1 & 1 \\
Surgical procedure (N) & & 6 \\
AVR & 8 & 45 \\
Mitral valve surgery & 3 & 1 \\
Coronary artery bypass graft & 42 & \\
Other & 0 & \\
\hline
\end{tabular}

EDTA, disodium edetate; SD, standard deviation; ASA, American Society of Anesthesiology; AVR, aortic valve replacement

* Significant difference between treatment groups $(p<0.05)$
Demographic variables were compared between the 2 treatment groups using the Wilcoxon rank sum test for continuous variables and the $\chi^{2}$ or Fisher exact test for discrete variables.

Statistical analysis of ionised calcium, ionised magnesium, total calcium, sodium, potassium, and phosphate concentrations was performed on the changes from baseline for each variable. Changes from baseline in clinical chemistry and haemodynamic variables were compared between treatment groups at each time point using analyses of covariance (ANCOVA), with study site, anaesthetic regimen, baseline value, and duration of anaesthesia (clinical chemistry only) as covariates. The possibility that either treatment formulation affected concentrations of ionised calcium or magnesium was further investigated by looking at the correlation between drug dosages (both induction and maintenance) and these electrolytes using a least squares method.

Time to onset of anaesthesia and recovery times were compared between treatment groups using ANCOVA, with study site as a covariate. The ANCOVA models evaluating treatment effects on recovery times also included anaesthetic regimen, duration of anaesthesia, and core body temperature as covariates.

\section{Results}

A total of 103 patients were enrolled in the study at 5 trial sites. One patient withdrew before receiving trial drug, thus 102 (51 propofol EDTA, 51 propofol) received study medication and were evaluated for safety. Seven patients were withdrawn prior to the end of the study: 1 for agitation (propofol EDTA); 3 for unanticipated surgical complexity (propofol EDTA); 2 for bleeding (propofol); and one for unanticipated difficult airway (propofol). Ninety patients were evaluable for data are presented in the text as mean \pm standard deviation (SD). 
Fig.1 Mean $(+$ SE $)$ concentration of ionised calcium in whole blood. Normal range $=$ $1.0-1.3 \mathrm{mmol} / \mathrm{L}$

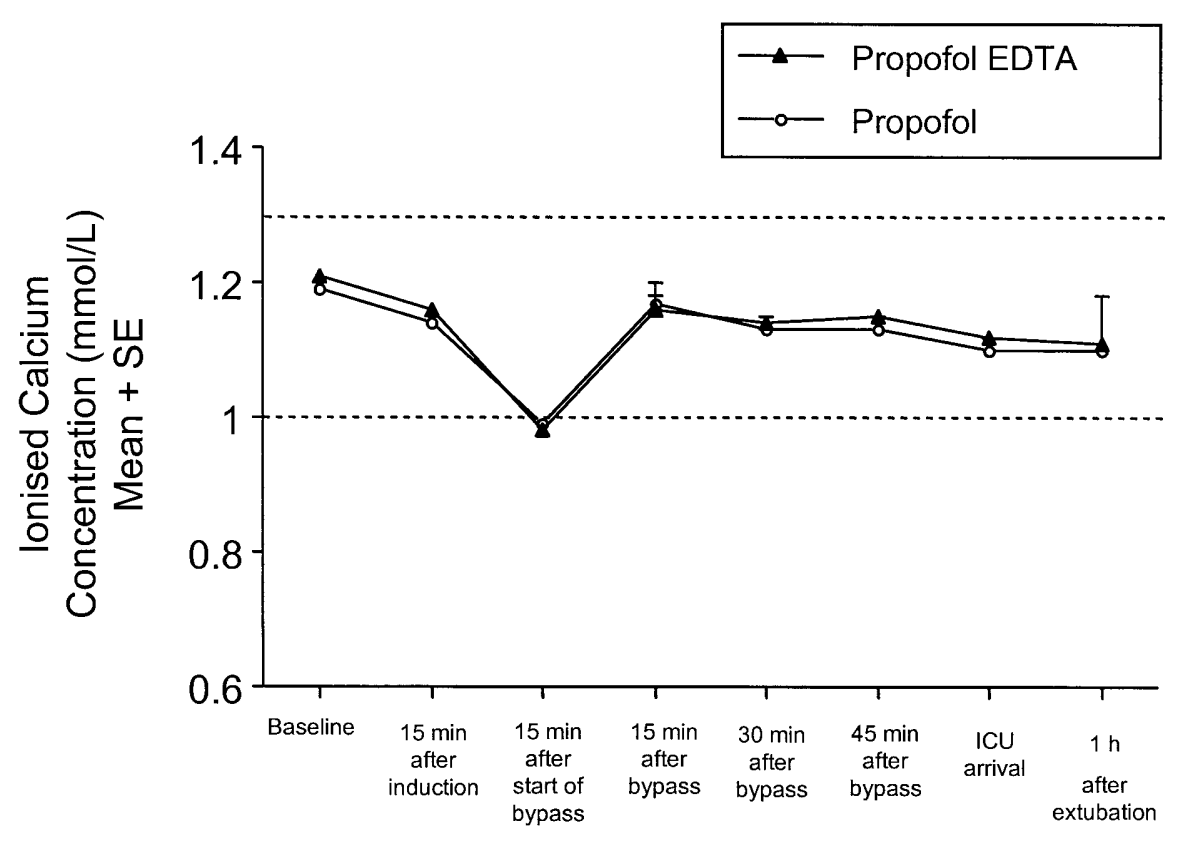

Table 2 Exposure of patients to study medications

\begin{tabular}{|c|c|c|c|c|}
\hline \multirow[t]{3}{*}{ Trial Drug } & \multicolumn{4}{|c|}{ Treatment Formulation } \\
\hline & \multicolumn{2}{|c|}{ Propofol EDTA* } & \multicolumn{2}{|l|}{ Propofol $\dagger$} \\
\hline & $\begin{array}{l}\text { Primary } \\
\text { Anaesthetic }\end{array}$ & $\begin{array}{l}\text { Adjunctive } \\
\text { Anaesthetic }\end{array}$ & $\begin{array}{l}\text { Primary } \\
\text { Anaesthetic }\end{array}$ & $\begin{array}{l}\text { Adjunctive } \\
\text { Anaesthetic }\end{array}$ \\
\hline $\begin{array}{l}\text { Propofol EDTA or propofol, mean } \pm \\
\text { Induction dose }(\mathrm{mg}) \\
\text { Maintenance dose }(\mathrm{mg}) \\
\text { Maintenance rate }(\mathrm{mg} / \mathrm{kg} \text { per min) } \\
\text { Dose } 1 \mathrm{~h} \text { after ICU entry }(\mathrm{mg})\end{array}$ & $\begin{aligned} 162 & \pm 88 \\
2733 & \pm 820 \\
0.11 & \pm 0.02 \\
152 & \pm 75\end{aligned}$ & $\begin{aligned} 75 & \pm 94 \\
1421 & \pm 419 \\
0.05 & \pm 0.01 \\
134 & \pm 67\end{aligned}$ & $\begin{array}{c}152 \pm 87 \\
2835 \pm 758 \\
0.12 \pm 0.02 \\
129 \pm 59\end{array}$ & $\begin{aligned} 54 & \pm 46 \\
1504 & \pm 434 \\
0.06 & \pm 0.01 \\
107 & \pm 62\end{aligned}$ \\
\hline $\begin{array}{l}\mathrm{Na}_{2} \mathrm{EDTA}, \text { mean } \pm \mathrm{SD} \ddagger \\
\text { Induction dose }(\mu \mathrm{g}) \\
\text { Maintenance dose }(\mu \mathrm{g})\end{array}$ & $\begin{array}{c}809 \pm 438 \\
13,667 \pm 4100\end{array}$ & $\begin{array}{c}375 \pm 471 \\
7102 \pm 2094\end{array}$ & $\begin{array}{l}\text { NA } \\
\text { NA }\end{array}$ & $\begin{array}{l}\text { NA } \\
\text { NA }\end{array}$ \\
\hline $\begin{array}{l}\text { Sufentanil, mean } \pm \text { SD } \\
\text { Induction dose }(\mu \mathrm{g}) \\
\text { Maintenance dose }(\mu \mathrm{g}) \\
\text { Maintenance rate }(\mathrm{ng} / \mathrm{kg} \text { per min }) \\
\text { Dose } 1 \mathrm{~h} \text { after ICU entry }(\mu \mathrm{g})\end{array}$ & $\begin{array}{r}47 \pm 32 \\
152 \pm 75 \\
6.2 \pm 3.1 \\
4.7 \pm 1.3\end{array}$ & $\begin{array}{r}201 \pm 115 \\
486 \pm 237 \\
19.5 \pm 9.5 \\
4.7 \pm 1.2\end{array}$ & $\begin{aligned} 37 & \pm 24 \\
155 & \pm 92 \\
6.6 & \pm 3.3 \\
5.2 & \pm 1.4\end{aligned}$ & $\begin{array}{c}217 \pm 102 \\
457 \pm 211 \\
20.6 \pm 10.4 \\
4.6 \pm 1.4\end{array}$ \\
\hline
\end{tabular}

EDTA, disodium edetate; SD, standard deviation; ICU, intensive care unit; NA, not applicable

* Mean duration of exposure to anaesthesia, $302.7 \pm 67.5 \mathrm{~min}$

all variables (44 propofol EDTA, 46 propofol). Aside from a small difference in body weight, there were no significant differences in demographic variables between patients assigned to propofol EDTA and those assigned to propofol (Table 1).

Patients in both treatment groups were maintained on anaesthesia in the operating room for approximately 5 hours (propofol EDTA, $302.7 \pm 67.5 \mathrm{~min}$; propofol, $301.1 \pm 47.5 \mathrm{~min})$. Exposure of patients to the treatment formulations and to sufentanil during induction and $\dagger$ Mean duration of exposure to anaesthesia, $301 \pm 47.5 \mathrm{~min}$ $\ddagger$ Estimated from propofol EDTA dose

maintenance was similar between treatment groups (Table 2).

The concentration of ionised calcium decreased from baseline in both treatment groups, and the magnitude of change was similar between groups at all assessment times ( $p=$ NS) (Fig.1). Only during bypass did the mean concentration of ionised calcium decrease to below the normal range $(1.0-1.3 \mathrm{mmol} / \mathrm{L})$ to $0.98 \pm$ $0.07 \mathrm{mmol} / \mathrm{L}$ in the propofol EDTA group and to $0.99 \pm 0.10 \mathrm{mmol} / \mathrm{L}$ in the propofol group $(p=\mathrm{NS})$. 


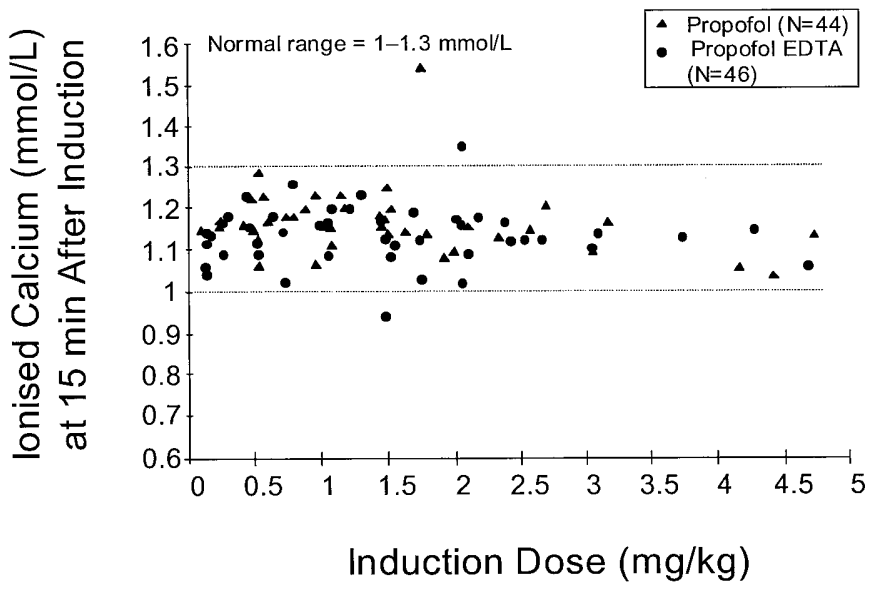

Fig. 2 Ionised calcium concentration at 15 minutes after induction dose $(\mathrm{N}=90)$

The proportion of patients with hypocalcaemia (ionised calcium concentration between 0.7 and $1 \mathrm{mmol} / \mathrm{L}$ ) was also similar between the propofol EDTA group $(65 \%)$ and the propofol group (59\%). One patient who received propofol as adjunctive anaesthesia had an ionised calcium concentration $<0.7 \mathrm{mmol} / \mathrm{L}$ $(0.48 \mathrm{mmol} / \mathrm{L}) 15$ minutes after CPB. There was no relationship between dose of propofol EDTA or propofol and ionised calcium concentrations (Fig.2) even at propofol induction doses of 4 to $5 \mathrm{mg} / \mathrm{kg}$.

The mean concentration of total calcium decreased to below normal levels in both treatment groups after surgery, decreasing from $9.20 \pm 0.44 \mathrm{mg} / \mathrm{dL}$ at baseline to $7.36 \pm 0.55 \mathrm{mg} / \mathrm{dL} 1$ hour after extubation in the propofol EDTA group and from $9.06 \pm 0.45 \mathrm{mg} / \mathrm{dL}$ to
$7.31 \pm 0.45 \mathrm{mg} / \mathrm{dL}$ in the propofol group. During the same period, increases were recorded in PTH concentrations from $40.04 \pm 19.18 \mathrm{pg} / \mathrm{mL}$ to $67.60 \pm 36.28 \mathrm{pg} / \mathrm{mL}$ in the propofol EDTA group and from $40.55 \pm 16.27 \mathrm{pg} /$ $\mathrm{mL}$ to $62.27 \pm 36.15 \mathrm{pg} / \mathrm{mL}$ in the propofol group.

The mean concentration of ionised magnesium changed little throughout the study in the 2 treatment groups (Fig. 3) and demonstrated no correlation with dosage of propofol EDTA or propofol. Mean magnesium concentration decreased slightly at 15 minutes after induction and then increased to levels above baseline for the remainder of the study. At all times, the mean concentration of magnesium remained within normal limits.

Mean serum concentrations of potassium and inorganic phosphate were equivalently decreased from baseline values in both treatment groups upon arrival in the ICU. However, the mean values at ICU arrival remained within normal ranges and returned to baseline values within $1 \mathrm{~h}$ of extubation. The mean serum concentration of sodium was unchanged throughout these timepoints (baseline, ICU arrival and $1 \mathrm{~h}$ after extubation).

Mean BUN and creatinine values remained within normal limits. Mean baseline BUN $(16.28 \mathrm{mg} / \mathrm{dL}$ in the propofol EDTA group and $16.00 \mathrm{mg} / \mathrm{dL}$ in the propofol group) and creatinine concentrations $(1.02 \mathrm{mg} / \mathrm{dL}$ in the propofol EDTA group and the propofol group) in both treatment groups decreased from baseline to ICU admission values (BUN: $13.24 \mathrm{mg} / \mathrm{dL}$ in the propofol EDTA group and $12.94 \mathrm{mg} / \mathrm{dL}$ in the propofol group; creatinine, $0.92 \mathrm{mg} / \mathrm{dL}$ in the propofol EDTA group and $0.86 \mathrm{mg} / \mathrm{dL}$ in the propofol group). Changes from baseline in these variables did not differ between treatment groups during the study.
Fig.3 Mean ( + SE) concentration of ionised magnesium in serum. Normal range $=$ $0.45-0.65 \mathrm{mmol} / \mathrm{L}$

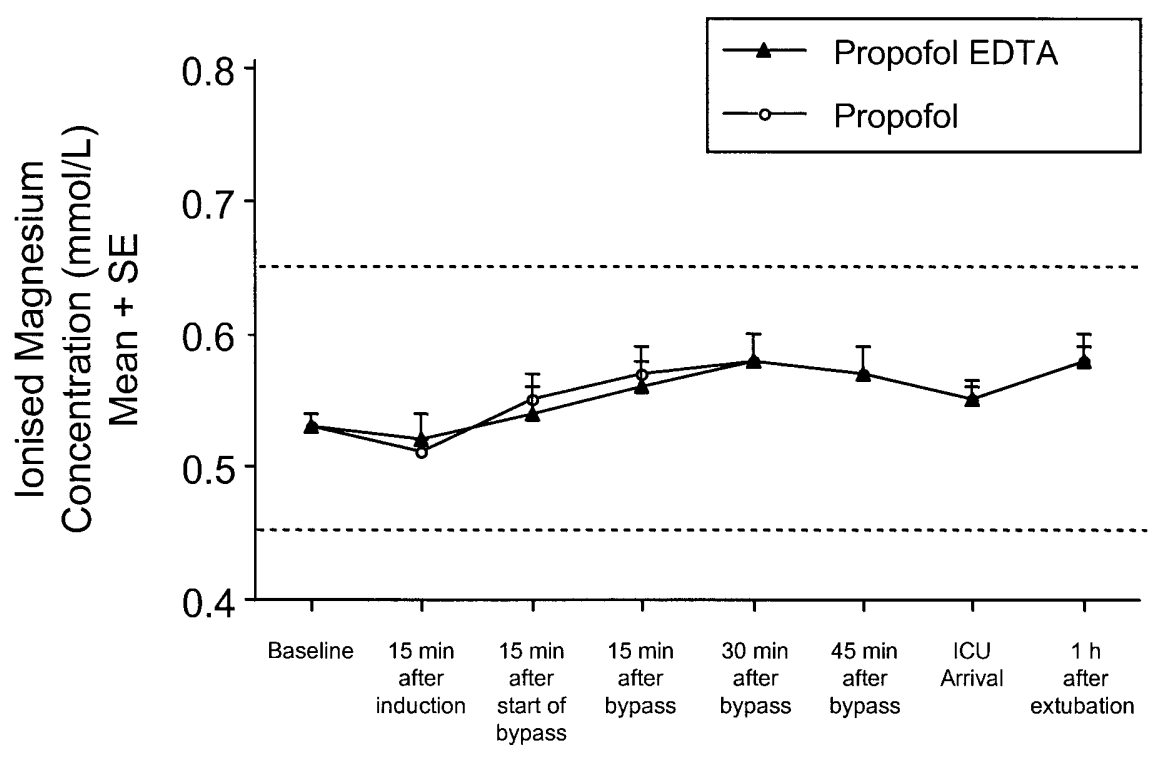




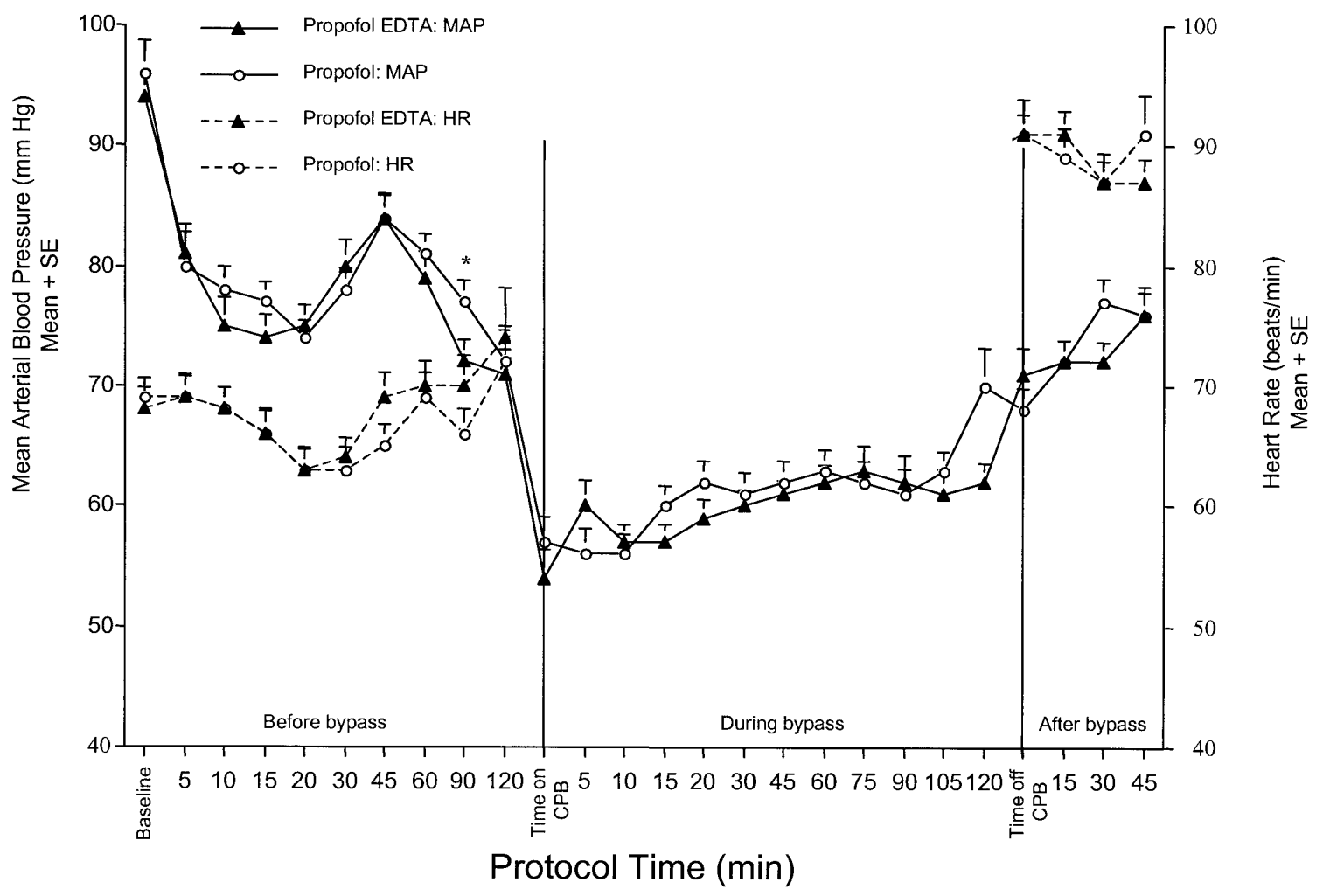

Fig. 4 Mean arterial pressure (MAP) and heart rate (HR) during cardiac surgery. ${ }^{*} p<0.05$

Propofol and propofol EDTA caused a decrease in mean arterial pressure, heart rate, and cardiac output during induction (Fig. 4). Decreases from baseline in mean systolic and diastolic blood pressures as well as in mean arterial pressure were observed throughout the study in both treatment groups. At 90 minutes after induction, patients randomised to propofol EDTA had statistically larger decreases in blood pressure than those randomised to propofol; however, this single statistically significant difference was not clinically meaningful. Changes in heart rate were minimal during induction of anaesthesia (Fig.4). Following bypass, increases in mean heart rate from baseline were observed in both treatment groups, with no significant differences between groups. The proportion of patients with tachycardia during surgery was relatively low (14\% propofol EDTA, $8 \%$ propofol) and did not differ significantly between treatment groups. Hypertension occurred in $63 \%$ and $60 \%$ of patients receiving propofol EDTA and propofol, respectively $p=$ NS.

Among the 102 patients who received one of the treatment formulations, 25 (49\%) of those who received propofol EDTA and $23(45 \%)$ of those who received propofol experienced at least one adverse event during the study (Table 3). For propofol EDTA, bleed- ing and hypotension were the most frequently reported adverse events (each was reported for $10 \%$ of patients). For propofol, bleeding was the most frequently reported adverse event, occurring in $20 \%$ of patients. The treatment groups were similar with respect to concomitant medications received by patients. Although most patients in both treatment groups received preparations containing calcium and magnesium, the use of these medications was similar between groups.

The time to onset of anaesthesia and the time to recovery did not differ significantly between treatment groups. Among patients receiving one of the treatment formulations as the primary anaesthetic agent, those randomised to propofol EDTA had an average of $184 \pm 137 \mathrm{~s}$ to induction of anaesthesia (ie, loss of eyelash reflex) compared with $180 \pm 119 \mathrm{~s}$ for patients randomised to propofol.

The interval between discontinuation of anaesthesia and the point at which patients responded to verbal commands averaged $160 \pm 177 \mathrm{~min}$ (propofol EDTA group) and $234 \pm 342 \mathrm{~min}$ (propofol group). More than half of the patients in each treatment group had Modified Ramsay Sedation Scale scores within the target range of 2 to 5 within 90 minutes after arrival in the ICU. Among patients randomised to propofol EDTA and to propofol, respective mean recovery times were $235 \pm 242$ min and $395 \pm 548$ min until spontaneous ventilation, $725 \pm 1148 \mathrm{~min}$ and $590 \pm 691 \mathrm{~min}$ until extuba- 
Table 3 Most frequently reported adverse events*

\begin{tabular}{|c|c|c|c|}
\hline \multirow[t]{2}{*}{ Body System } & \multirow[t]{2}{*}{ Adverse Event } & \multicolumn{2}{|c|}{ Number of Patients With Adverse Events (\%) by Formulation $\dagger$} \\
\hline & & $\begin{array}{l}\text { Propofol EDTA } \\
(\mathrm{N}=51)\end{array}$ & $\begin{array}{l}\text { Propofol } \\
(\mathrm{N}=51)\end{array}$ \\
\hline Cardiovascular & $\begin{array}{l}\text { Bleeding } \\
\text { Hypotension } \\
\text { Hypertension } \\
\text { Atrial fibrillation } \\
\text { Supraventricular tachycardia } \\
\text { ECG abnormality } \\
\text { Cardiac arrest } \\
\text { Ventricular tachycardia }\end{array}$ & $\begin{array}{l}5(10 \%) \\
5(10 \%) \\
4(8 \%) \\
3(6 \%) \\
2(4 \%) \\
2(4 \%) \\
1(2 \%) \\
1(2 \%)\end{array}$ & $\begin{array}{c}10(20 \%) \\
2(4 \%) \\
1(2 \%) \\
1(2 \%) \\
1(2 \%) \\
0(0 \%) \\
2(4 \%) \\
2(4 \%)\end{array}$ \\
\hline Gastrointestinal & $\begin{array}{l}\text { Nausea } \\
\text { Vomiting }\end{array}$ & $\begin{array}{l}3(6 \%) \\
2(4 \%)\end{array}$ & $\begin{array}{l}3(6 \%) \\
3(6 \%)\end{array}$ \\
\hline Nervous system & Chills & $4(8 \%)$ & $1(2 \%)$ \\
\hline Respiratory & Hypoxia & $2(4 \%)$ & $0(0 \%)$ \\
\hline
\end{tabular}

EDTA, disodium edetate; ECG, electrocardiogram

* Events occurring in 2 or more patients

tion, and $15.1 \pm 7.4 \mathrm{~h}$ and $15.6 \pm 12.7 \mathrm{~h}$ until patients could eat food by mouth $(p=\mathrm{NS})$.

Concomitant cardiovascular medications received by patients included beta-blockers, antihypertensive drugs, coronary vasodilators, inotropic agents, and antiarrhythmic drugs. These drugs were required by $10 \%$ of patients in the propofol EDTA group and by $6 \%$ in the propofol group $(p=\mathrm{NS})$.

\section{Discussion}

The inclusion of EDTA as an antimicrobial agent in the current formulation of propofol did not affect calcium, magnesium, phosphate, sodium, or potassium concentrations, renal function, or haemodynamic changes in patients undergoing cardiac surgeries requiring $\mathrm{CPB}$. Changes in these variables appearing during and after $\mathrm{CPB}$ were generally attributable to aspects of the surgical procedure that were unrelated to anaesthesia with propofol EDTA or propofol. Although the chelating action of EDTA theoretically is a concern in cardiac patients, the low concentration of EDTA $(0.005 \%)$ contained in the marketed formulation of propofol appears well tolerated.

This study confirms the decrease in ionised calcium concentration that occurs during CPB and its return to normal following CPB. No significant changes were found in ionised magnesium concentrations during and after CPB. Previous studies using total magnesium demonstrated significant decreases during and after $\mathrm{CPB}$ [18]. In this study, changes in ionised calcium concentrations during cardiac surgery were characteristic of those previously reported in patients undergoing CPB $[1,18]$ and were unrelated to the presence of EDTA. The normal response of the calcium-parathyroid axis to de- $\dagger$ Treatment differences were not statistically significant for any adverse event

creased calcium concentration was apparently preserved, with the mean serum concentration of PTH increasing from baseline to the postoperative period in both treatment groups.

The transient decrease in ionised calcium concentration observed in this study could result from several events, beginning with the haemodilution associated with CPB. In addition, blood products containing citrate-phosphate-dextrose, a preservative that exerts its anticoagulant action by chelating calcium, may have decreased calcium concentrations [4, 19]. Heparin has also been shown to bind ionised calcium [1]. Finally, diuretics, which were administered to $94 \%$ of patients in the propofol EDTA group and to $76 \%$ in the propofol group, may promote high losses of calcium in the urine [1]. A decrease in calcitriol levels may predispose to decreasing ionised calcium concentrations. However, a previous study [18] reported normal levels in patients undergoing $\mathrm{CPB}$.

Decreases in total serum magnesium concentrations are often reported during CPB [3, 20, 21]. Ionised magnesium concentrations were measured in this study and were found to remain within normal limits. Changes were not evident with either formulation of propofol in this study. Other studies have reported transient impairment of solute reabsorption during CPB [22] and decreases in serum potassium concentrations comparable to those observed in our study $[4,20]$. Although EDTA can occasionally be toxic to renal tubules at high doses ( 2 to $3 \mathrm{mg} / \mathrm{d}),[23]$ the low concentration found in the propofol EDTA formulation appears to have no adverse impact on kidney function.

Haemodynamic changes were consistent with those reported with other anaesthetic regimens $[1,18]$ and did not differ significantly between propofol formulations. Like many other sedative-hypnotic drugs, propo- 
fol has been shown in previous studies to cause reductions in blood pressure at induction secondary to decreases in preload and afterload. The $25 \%$ decrease in this study is similar to the $15 \%$ to $30 \%$ decreases seen in other studies [6-9, 24]. At only one time point (90 minutes after induction) were there statistically significant differences between the 2 formulations in this study. Although chelation of calcium could theoretically result in hypotension and decreased cardiac output, the fact that concentrations of ionised calcium were similar between groups makes EDTA an unlikely cause of this observation. In addition, the difference was observed only at this single time point and was not considered to be clinically significant.

By the end of bypass, mean arterial pressure remained below baseline levels but continued to increase. Such increases in blood pressure and in heart rate are typical during CPB and are presumably mediated by release of catecholamines [7, 9, 25]. Hypertension (systolic blood pressure $>140 \mathrm{~mm} \mathrm{Hg}$ ) occurred in $63 \%$ and $60 \%$ of patients receiving propofol EDTA and propofol, respectively, at some point during induction and maintenance of anaesthesia. However, only one episode of hypertension was classified as an adverse event attributable to a treatment formulation. This event, which occurred at intubation during the use of propofol EDTA, responded to treatment with nitroglycerin and nitroprusside. Although published studies indicate that propofol produces greater reductions in systolic blood pressure and mean arterial pressure than other regimens, such as sufentanil-enflurane $[6,7]$ and midazolam-sufentanil, [9] the incidence of cardiac ischaemic events with propofol is low [6, 7]. No patient in either group was reported to have a cardiac ischaemic event in this study.

Changes in heart rate occurred in parallel between the 2 treatment groups throughout the study period and were consistent with the results of several published studies of propofol in patients undergoing cardiac surgery $[6-9,24]$. Mean heart rate at the end of bypass was well above baseline readings but similar in both groups. However, the proportion of patients with tachycardia during surgery was relatively low (14\% in the propofol EDTA group and $8 \%$ in the propofol group) and did not differ significantly between treatments.

The propofol EDTA and propofol preparations demonstrated similar efficacy as determined by time to loss of eyelash reflex and return to spontaneous respirations and extubation. Recovery times of patients in the ICU were similar to those reported previously with use of propofol (plus sufentanil) in CPB surgery [6].

\section{Conclusion}

The addition of EDTA to propofol had no clinically significant effects on calcium and magnesium profiles, renal function, haemodynamic variables, or adverse effects during induction and maintenance of anaesthesia or during postoperative ICU sedation in patients undergoing cardiac surgery.

Acknowledgements The authors acknowledge Kendall Wills Sterling, ELS, and James A. Shiffer, RPh, for editorial assistance.

\section{References}

1. Catinella FP, Cunningham JN Jr, Strauss ED et al. (1983) Variations in total and ionized calcium during cardiac surgery. J Cardiovasc Surg (Torino) 24: 593-602

2. Olinger GN, Hottenrott C, Mulder DG et al. (1976) Acute clinical hypocalcemic myocardial depression during rapid blood transfusion and postoperative hemodialysis: a preventable complication. J Thorac Cardiovasc Surg 72: 503-511

3. Aglio LS, Stanford GG, Maddi R et al. (1991) Hypomagnesemia is common following cardiac surgery [see comments]. J Cardiothorac Vasc Anesth 5: 201-208

4. Vaska PL (1992) Fluid and electrolyte imbalances after cardiac surgery. AACN Clin Issues Crit Care Nurs 3: 664-671
5. Kaplan J, Guffin A, Mikula S, Dolman J, Profeta J (1988) Comparative hemodynamic effects of propofol and thiamylal sodium during anesthetic induction for myocardial revascularisation. J Cardiothoracic Anesthesia 3: 297-302

6. Hall R, Murphy J, Landymore R et al. (1993) Myocardial metabolic and hemodynamic changes during propofol anesthesia for cardiac surgery in patients with reduced ventricular function. Anesth Analg 77: 680-689

7. Hall R, Murphy J, Moffitt E et al. (1991) A comparison of the myocardial metabolic and haemodynamic changes produced by propofol-sufentanil and enflurane-sufentanil anaesthesia for patients having coronary artery bypass graft surgery. Can J Anaesth 38: 996-1004
8. Phillips AS, McMurray TJ, Mirakhur RK, Gibson FM, Elliott P (1993) Propofol-fentanyl anaesthesia in cardiac surgery: a comparison in patients with good and impaired ventricular function [see comments]. Anaesthesia 48: 661-663

9. Kleinschmidt S, Grundmann U, Janneck U et al. (1997) Total intravenous anaesthesia using propofol, gamma-hydroxybutyrate or midazolam in combination with sufentanil for patients undergoing coronary artery bypass surgery. Eur J Anaesthesiol 14: 590-599

10. Wahr JA, Plunkett JJ, Ramsay JG et al. (1996) Cardiovascular responses during sedation after coronary revascularization. Incidence of myocardial ischemia and hemodynamic episodes with propofol versus midazolam. Institutions of the McSPI Research Group. Anesthesiology $84: 1350-1360$ 
11. Snellen F, Lauwers P, Demeyere R, Byttebier G, Van Aken H (1990) The use of midazolam versus propofol for short-term sedation following coronary artery bypass grafting. Intensive Care Med 16: 312-316

12. Bennett SN, McNeil MM, Bland LA et al. (1995) Postoperative infections traced to contamination of an intravenous anesthetic, propofol [see comments]. N Engl J Med 333: 147-154

13. Thomas DV (1991) Propofol supports bacterial growth [letter]. Br J Anaesth 66: 274

14. Ashoori M, Ohta M, Ohsuka S et al. (1999) Antibacterial activities of new synthetic divalent cation chelators. Microbiol Immunol 43: 311-316

15. Vaara M (1992) Agents that increase the permeability of the outer membrane. Microbiol Rev 56: 395-411

16. Kluck RM, McDougall CA, Harmon BV, Halliday JW (1994) Calcium chelators induce apoptosis-evidence that raised intracellular ionised calcium is not essential for apoptosis. Biochim Biophys Acta 1223: 247-254
17. Liesegang A, Riond JL, Wanner M (1999) Unexpected outcome after two consecutive infusions of disodium EDTA in dairy cows. Zentralbl Veterinarmed A 46: 149-154

18. Robertie PG, Butterworth JFt, Royster RL et al. (1991) Normal parathyroid hormone responses to hypocalcemia during cardiopulmonary bypass [published erratum appears in Anesthesiology 1992 Jan;76(1):158] [see comments]. Anesthesiology 75: 43-48

19. Howland WS, Schweizer O, Carlon GC, Goldiner PL (1977) The cardiovascular effects of low levels of ionized calcium during massive transfusion. Surg Gynecol Obstet 145: 581-586

20. Storstein L, Nitter-Hauge S, Fjeld N (1979) Effect of cardiopulmonary bypass with heparin administration on digitoxin pharmacokinetics, serum electrolytes, free fatty acids, and renal function. J Cardiovasc Pharmacol 1: 191-204
21. Togashi H, Kasuda H, Inoue S, Hotta Y, Fukuda H (1997) [Serum and urinary magnesium during and after cardiac surgery]. Masui 46: 1336-1341

22. Licker M, Schweizer A, Hohn L, Morel DR (1999) Chronic angiotensin converting inhibition does not influence renal hemodynamic and function during cardiac surgery. Can J Anaesth 46: 626-634

23. DIPRIVAN [package insert]. Wilmington, DE: AstraZeneca,a Business Unit of Zeneca, Inc. 1998

24. Vermeyen KM, Erpels FA, Janssen LA, Beeckman CP, Hanegreefs GH (1987) Propofol-fentanyl anaesthesia for coronary bypass surgery in patients with good left ventricular function. $\mathrm{Br} \mathrm{J}$ Anaesth 59: 1115-1120

25. Lindgren L, Yli-Hankala A, Randell T et al. (1993) Haemodynamic and catecholamine responses to induction of anaesthesia and tracheal intubation: comparison between propofol and thiopentone [see comments]. Br J Anaesth 70: 306-310 